\title{
EVALUATION OF IN VITRO ANTIUROLITHIATIC ACTIVITY OF CHLORIS BARBATA
}

\author{
NIHARIKA M. , HARSHITHA V., ASHWINI P., SRIVINYA B., HIMABINDHU J., RAMANJANEYULU K.
}

Department of Pharmacognosy, Vishnu Institute of Pharmaceutical Education and Research, Narsapur, Medak, Telangana, India Email: manneniharika9@gmail.com

Received: 23 Jan 2018, Revised and Accepted: 08 Apr 2018

ABSTRACT

Objective: The present study was undertaken to evaluate the in vitro antiurolithiatic activity of the medicinal plant Chloris barbata.

Methods: The crude plant extract was prepared by Soxhlet extraction method.

Results: Both Ethanolic and Aqueous extracts showed their maximum efficiencies in the dissolution of calcium oxalate crystals. Ethanolic extract was even more efficient than Aqueous extract in the dissolution of calcium oxalate crystals. Our results have clearly indicated that the Aqueous and Ethanolic leaf extracts of Chlorisbarbata were quite promising for further studies in this regard. In this study, Neeri was used as standard drug.

Conclusion: This study has given primary evidence for Chloris barbata as the plant which possess antiurolithiatic property.

Keywords: In vitro antiurolithiatic activity, Aqueous extract, Ethanolic extract, Urolithiasis, Chlorisbarbata, Neeri

(C) 2018 The Authors. Published by Innovare Academic Sciences Pvt Ltd. This is an open access article under the CC BY license (http://creativecommons.org/licenses/by/4.0/) DOI: http://dx.doi.org/10.22159/ijcpr.2018v10i3.27342

\section{INTRODUCTION}

Plants provide food, raw materials for medicine and various other requirements for the very existence of life from the origin of human beings [1]. Even the current conventional medicine is using a lot of plant-derived chemicals as therapeutic agents. The overuse of synthetic drugs results in higher incidence of adverse drug reactions has motivated humans to return to nature for safe remedies. Herbs and herbal drugs have created interest among the people by its clinically proven effects [2]. Therefore, there is a compelling need for detailed scientific validation of all traditional medicinal plant drugs to establish their efficacy and safety in light of modern science.

Kidney stone disease is a multi-factorial disorder resulting from the combined influence of epidemiological, biochemical and genetic risk factors [3]. Urolithiasis is considered as the third most common affliction of the urinary tract. It refers to the solid non-metallic minerals in the urinary tract. It is a complex process that is a consequence of an imbalance between promoters and inhibitors in the kidney. The formation of kidney stones involves several phytochemical events beginning with crystal nucleation, aggregation and end with retention within the urinary tract. Among the several types of kidney stones, the most common are calcium oxalate stones representing up to $80 \%$ of the analyzed stones [4]. Calcium-containing stones may be in the form of pure calcium oxalate $(50 \%)$ or calcium phosphate $(5 \%)$ and a mixture of both $(45 \%)$ followed by magnesium phosphate (15-20\%), uric 5 acid (10\%) and cystine (1\%) [5].

It is estimated that at least $10 \%$ of the population in the industrialized part of the world is afflicted by urinary tract diseases and among these kidney stones are common with an annual incidence of $0.5-1.9 \%$. About $12 \%$ of the population of India is expected to have urinary stones and out of that $50 \%$ of cases encounter loss of one or both 2 kidneys with or without renal damage up to some extent [2].

Stone disease is $2-3$ times more common in males than in females. It 5 has a reoccurrence rate of $70-81 \%$ in males and $47-60 \%$ in females $^{5}$. In spite of substantial progress in pathophysiology and treatment of urolithiasis, there is no satisfactory drug being used in clinical therapy. Kidney dialysis, endoscopic stone removal and extracorporeal shock wave lithotripsy are prohibitively costly and reoccurrence is quite common with these procedures [1].

Data from in vitro and in vivo clinical trials revealed that phytotherapeutic agents could be useful as an alternative therapy in the management of urolithiasis. Medicinal plants and their products are more useful because they promote the repair mechanism in naturalway ${ }^{1}$. Pharmacological and phytochemical prospecting of medicinal plants based on traditional knowledge can lead to the discovery of new drug and development of pharmacologically important products for human health care $^{6}$. Green medicines were safe and more dependable than the costly synthetic drugs, many of which have side effects [7].

The selected plant Chloris barbata has occupied an important place in Indian culture and folk medicines. This plant has been extensively in Ayurvedic system of medicine and is used throughout India. The plant shows various pharmacological activities like Anti-diabetic [8], Anti-helminthic, Anti-pyretic, Anti-inflammatory, Analgesic, Antibacterial [9] etc.

\section{MATERIALS AND METHODS}

\section{Plant material}

The leaves of Chloris barbata was collected in the month of august 2017 from Maddur village, Medak dist. of Telangana, India. The plant was authenticated by D. Venkateshwara Rao, Deputy Director, Telangana. Forest Academy, Dullapally, Hyderabad, Rangareddy District. The leaves were washed with tap water and dried under shade.

\section{Preparation of plant extract}

The leaves were shade dried and powdered. The crude plant extract was prepared by Soxhlet extraction method. $50 \mathrm{~g}$ of powdered plant material was extracted with $500 \mathrm{ml}$ of ethanol and water individually. The process of extraction was carried out up to 6 cycles, till the solvent in siphon tube of an extractor became colourless. The two extracts were filtered separately and evaporated to dryness using rotary evaporator. Further, the dried extracts were maintained in a refrigerator at $4{ }^{\circ} \mathrm{C}$ for further antiurolithiatic activity.

\section{Chemicals used}

Neeri, Sodium oxalate, Tris buffer, calcium chloride, Potassium permanganate (KMnO4), Sulphuric acid $\left(\mathrm{H}_{2} \mathrm{SO}_{4}\right)$.

\section{Investigation of in vitro antiurolithiatic activity test by titrimetry}

The experimental kidney stones of calcium oxalate ( $\mathrm{CaOx}$ ) were prepared in the laboratory by taking an equimolar solution of calcium chloride dehydrate in distilled water and sodium oxalate in 
$10 \mathrm{ml}$ of $2 \mathrm{~N} \mathrm{H}_{2} \mathrm{SO}_{4}$. Both were allowed to react in sufficient quantity of distilled water in a beaker, the resulting precipitate was calcium oxalate. The precipitate was freed from traces of sulphuric acid by ammonia solution, washed with distilled water and dried at $60^{\circ} \mathrm{C}$. The dissolution percentage of calcium oxalate was evaluated by taking exactly $1 \mathrm{mg}$ of calcium oxalate and $10 \mathrm{mg}$ of the extract, packed it together in the semi-permeable membrane of the egg as shown in the model designed given below. This was allowed to suspend in a conical flask containing $100 \mathrm{ml}$ of $0.1 \mathrm{M}$ Tris buffer. The first group served as blank containing only1 $\mathrm{mg}$ of calcium oxalate. The second group served as a positive control containing $1 \mathrm{mg}$ of calcium oxalate and along with the $10 \mathrm{mg}$ standard drugs, i.e. Neeri. The 3rd, 4th groups along with $1 \mathrm{mg}$ of calcium oxalate contain methanolic and aqueous, extracts. The conical flasks of all groups were kept in an incubator preheated to $37{ }^{\circ} \mathrm{C}$ for $2 \mathrm{~h}$. Remove the contents of semi-permeable membranes from each group into separate test tubes, add $2 \mathrm{ml}$ of $1 \mathrm{Nsulphuricacid} \mathrm{to} \mathrm{each} \mathrm{test} \mathrm{tube}$ and titrated with $0.9494 \mathrm{~N} \mathrm{KMnO4}$ till a light pink colour end point obtained. The amount of remaining undissolved calcium oxalate is subtracted from the total quantity used in the experiment, in the beginning, to know the total quantity of dissolved calcium oxalate by various solvent extracts [10].

\section{RESULTS AND DISCUSSION}

Drug therapy has developed in response to population health care [11] needs. There are many crucial areas in medicine such as liver diseases, arthritis, old age related problems, certain viral infections and cancer where the conventional medicine is devoid of satisfactory treatment. These are among the promising areas of research and development of medicines from the vast highly potential plant resources. Plants are also attractive sources for the development of novel and very effective and safe therapeutic agents against kidney procumbens. Herbal medicines are also in great demand in the developed world for primary health care because of their efficacy, safety and lesser side effects [12]. Unlike allopathic medicines which target is only one aspect of urolithiatic pathophysiology, most of the plant-based therapy has been shown to be effective at different stages of stone pathophysiology [13]. About $80 \%$ of the world populations rely on the use of traditional medicine which is predominantly based on plant materials [14]. Plant-based drug discovery programmes continue to provide an important source of new drug leads [15]. Lithiasis (stone formation) is an important cause for acute and chronic renal failure, includes both nephrolithiasis (stone formation in kidney) and urolithiasis (stone formation in ureter or bladder or both). Among the various kinds of stones identified, calcium stones occur mainly in Men, while phosphate stones formation is more in women [16].

This study evaluates the antiurolithiatic activity of Ethanolic and Aqueous extract of Chloris barbata. The highest percentage i.e. 87\% of calcium oxalate $\{\mathrm{CaOx}\}$ dissolution was observed in Ethanolic extract followed by an Aqueous extract which had a percentage dissolution of calcium oxalate was 76\%. Both Ethanolic extracts of Chlorisbarbata were found to be more effective in the dissolution of calcium oxalate than standard drug Neeri. From this study, it was observed that Aqueous and Ethanolic extracts of Chloris barbata showed their highest dissolution of calcium oxalate. Ethanolic extract was found to be even more effective than aqueous extract in the dissolution of calcium oxalate. This study has given primary evidence for Chloris barbata as the plant which possess lithotriptic property. This in vitro study has given lead data and shown that Aqueous and Ethanolic extracts are quite promising for further studies in this regard.

Table 1: Shows \% dissolution of calcium oxalate (CaOx) by Chlorisbarbata leaves extracts.

\begin{tabular}{lll}
\hline S. No. & \% of dissolution of calcium oxalate & Chlorisbarbata \\
\cline { 2 - 3 } & Groups & 0 \\
\hline 1. & Blank & 81 \\
2. & Positive Control & 87 \\
3. & Ethanolic extract & 76 \\
4. & Aqueous extract & \\
\hline
\end{tabular}

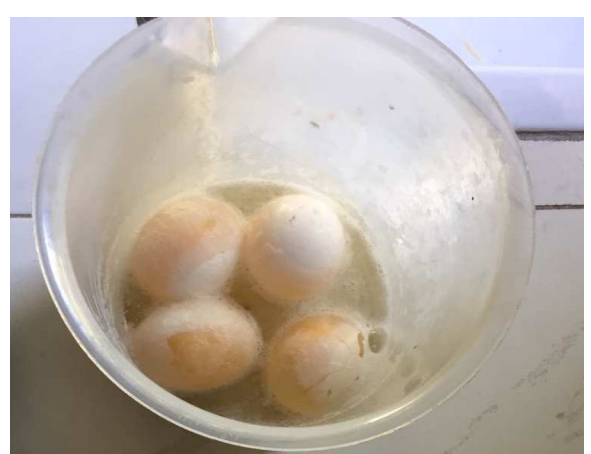

Fig. 1(a): Decalcification of eggshell in $10 \%$ acetic acid overnight

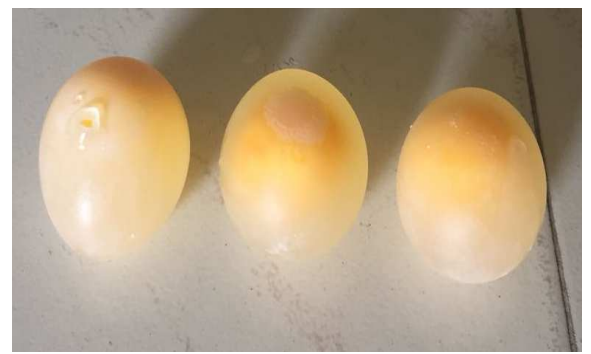

Fig. 1(b): Decalcified eggs

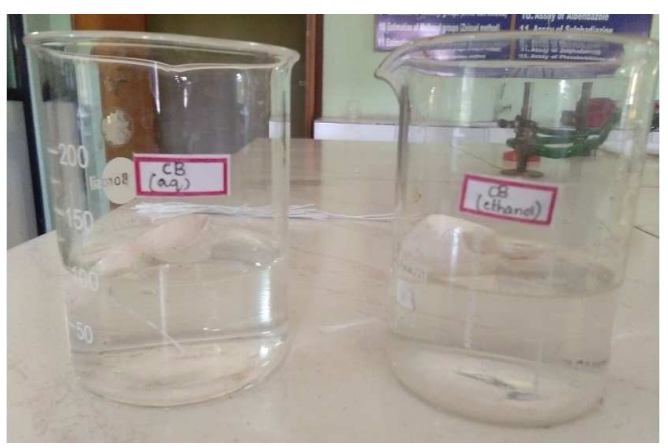

Fig. 1(c): Egg membrane along with the contents suspended into the $0.1 \mathrm{M}$ Tris buffer

\section{CONCLUSION}

In vitro urolithiasis has been performed on the selected plant Chloris barbata by using the standard drug, Neeri. The work was performed by using in vitro antiurolithiatic model for calculating percentage dissolution of kidney stone. Ethanolic leaf extracts of Chloris barbata shows the highest dissolution than standard drug Neeri. This study has given primary evidence for Chloris barbata as the plant which possess antiurolithiatic property.

\section{ACKNOWLEDGEMENT}

We sincerely thankful to our principal Dr. A. Ramesh and staff members, Director and chairman of our college Vishnu Institute of 
Pharmaceutical Education and Research (VIPER) for supporting us.

\section{AUTHORS CONTRIBUTIONS}

All the author have contributed equally

\section{CONFLICT OF INTERESTS}

Declared none

\section{REFERENCES}

1. Sumayyasikandari, Prathima Mathad. In vitro antiurolithiatic activity of Buteamonosperma Lam. and Nigella Sativa Linn. seeds. Ukaaz-Ann Phytomed 2015;4:105-7.

2. Sanjay kumar Gupta, Madhavsingh baghel, Chaturbhuja Bhuyan, B Ravi Shankar, Ashok BK, Panchakshari D Patil. Evaluation of the anti-urolithiatic activity of Pashanabhedadi Ghrita against experimentally induced renal calculi in rats. AYU Int Quarterly J Res Ayurveda 2012;33:429-34.

3. Atul Makasana, Vishavas Ranpariya, Dishant Desai, Jaymin Mendpara, Vivek Parekh. Evaluation for the anti-urolithiatic activity of Launaeaprocumbens against ethylene glycol-induced renal calculi in rats. Elsevier Toxicol Reports 2014;1:46-52.

4. Jagannath N, Somashekara S. Chikkannasetty, Govindadas D, Devasankaraiah G. Study of anti urolithiatic activity of Asparagus racemosus on albino rats. Indian J Pharmacol 2012;44:576-9.

5. Radhasinganallur Ramu, Ravi Doraiswamy, Hiran Mai Yadav. Antiurolithiatic activity of Aqueous bark extract of Crateva Magna Lour. (DC). Int J Res Ayurveda Pharm 2017;8:271-8.

6. Subramoniam. Present scenario, challenges and future perspectives in plant-based medicine development. Ukaaz Ann Phytomed 2014;3:31-6.
7. Subramoianm A. Phytomedicines for healthcare. Ukaaz Ann Phytomed 2014;3:1-3.

8. Arumugam Saravana Kumar, Subramanian Kavimani, Korlakunta NarasimhaJayaveera. Anti-diabetic and antihyperlipidemic effects of methanol extracts of Chloris barbata (SW.) in Streptozotocin-induced diabetic rats. Pelagia Res Library Eur J Exp Biol 2012;2:1346-53.

9. Bhargavi Sakala, Naresh Medarametla, Mahesh Batsala, Suryasagar Gopisetty, Sreekanth Nama. An evaluation of the antibacterial activity of root extracts of Chloris barbata sw. against staphylococcus aureus 9886 and Escherichia coli 1673. Int J Biopharma Res 2013;2:127-8.

10. Unnate Atodriya, Roshni Baard, Siddi Upadhya, Umesh Upadhyay. Antiurolithiatic activity of Dolichosbiflorus seeds. J Pharmacogn Phytochem 2013;2:209-13.

11. Michael Dickson, Jean Paul Gagnon. Key factors in the rising cost of new drug discovery and development. Nat Rev Drug Discovery 2004;3:417-29.

12. Kamboj VP. Herbal medicine. Curr Sci Assoc 2000;78:35-9.

13. Archana R. Dhole, Vikas R. Dhole, Chandrakant S. Magdum, Shreenivas Mohite. Herbal therapy for urolithiasis: a brief review. Res J Pharmacol Pharmacodynamics 2013;5:6-11.

14. Subramoniam A, P Pushpangadan. Development of phytomedicines for liver disease. Indian J Pharmacol 1999; 31:166-75.

15. Sanjay M, Jachak, Arvindsaklani. Challenges and opportunities in drug discovery from plants. Curr Sci Assoc 2007;92:1251-7.

16. Ramachandran S, Vijayakumar TM, Saisandeep V, Ramsai K, Dhanaraju MD. Antilithiatic activity of polyherbal extracts on ethylene glycol-induced lithiasis in rats. Eur J Biol Sci 2011;3:36-9. 